\title{
Numerical simulation of the 5-day and 16-day waves in the mesopause region
}

\author{
Yasunobu Miyoshi \\ Department of Earth and Planetary Sciences, Kyushu University, Fukuoka 812-8581, Japan
}

(Received August 4, 1998; Revised December 20, 1998; Accepted December 20, 1998)

\begin{abstract}
The behavior of the 5-day and 16-day waves in the mesopause region is examined by using a general circulation model. The results are as follows. The 5-day wave is largely unaffected by the zonal mean zonal wind distribution, and the symmetric structure about the equator is clearly seen in the mesopause region. The amplitude of the 16-day wave in the summer hemisphere of the stratosphere is small. However, above the upper mesosphere, the 16-day wave appears not only in the winter hemisphere but also in the summer hemisphere. The penetration of the 16-day wave from the winter hemisphere to the summer hemisphere occurs near the mesopause region. The 16-day wave is mainly excited by heating due to the moist convection in the troposphere, and the vertical penetration into the middle atmosphere occurs. Furthermore, a correlation between the geomagnetic variation and the wind variation associated with the 5-day and 16-day waves is discussed.
\end{abstract}

\section{Introduction}

It is well known that long period oscillations (an order of $10^{0}-10^{1}$ days) appear in the mesopause region. By using radar observation at Alaska, Williams and Avery (1992) showed that wind oscillations with about 2, 5 and 16 days periods appeared in the upper mesosphere and lower thermosphere. Espy and Witt (1996) showed that a quasi 16-day oscillation had large amplitude in the summer season of the mesopause region.

By using UARS/HRDI data, Wu et al. (1994) investigated the global structure of the 5-day wave $((s, n-s)=(1,1)$ mode of the normal mode Rossby waves; $s$ is the zonal wavenumber, and $n$ is the meridional index number such that $n-s-1$ is the number of nodes between the poles) in the mesopause region. They showed that the observed structure of the 5-day wave was similar to the structure of the theoretically expected normal mode Rossby waves. The amplitude of the zonal wind component of the 5-day wave is $10-25 \mathrm{~ms}^{-1}$ in the mesopause region. However, the relation of the stratospheric 5-day wave and the 5-day wave in the mesopause region is unclear.

Only few studies about the global structure of the 16-day wave $((1,3)$ mode) in the mesopause region have been reported. Forbes et al. (1995) investigated behaviors of the 16-day wave in the summer hemisphere of the mesopause region by using a GSWM (global scale wave model). They showed that the 16-day wave appeared in high-latitude summer hemisphere. However, seasonal variation and global structure of the 16-day wave in the mesopause region, and its relation to the stratospheric 16-day wave are not clear. In this study, we investigate the behavior of the 5-day and 16-day waves in the mesopause region simulated by a GCM (general circulation model). The purpose of this study is to investigate seasonal variation and global structure of the 5-

Copy right (C) The Society of Geomagnetism and Earth, Planetary and Space Sciences (SGEPSS); The Seismological Society of Japan; The Volcanological Society of Japan; The Geodetic Society of Japan; The Japanese Society for Planetary Sciences. day and 16-day waves, and their relation to the stratospheric 5-day and 16-day waves. Excitation sources of normal mode Rossby waves in the lower atmosphere are also unclear. We also investigate excitation sources of the 16-day wave by a series of GCM experiments.

Forbes and Leveroni (1992) and Kohsiek et al. (1995) suggested that the geomagnetic oscillation with a 16 days period might be induced by the wind variation associated with the 16-day wave. We discuss a possibility that the 5-day and 16-day waves in the lower thermosphere induce the geomagnetic oscillation. The description of a GCM is presented in Section 2. Results and discussion are presented in Sections 3 and 4, respectively. Summary follows in Section 5.

\section{Model Descriptions}

In this study, a GCM developed at Kyushu University is used. The GCM is a global spectral model with the triangular truncation at wavenumber 21 in the horizontal direction. The GCM has 55 vertical levels and contains the region from the ground to about $150 \mathrm{~km}$ height. The detailed descriptions of the GCM are found in Miyahara and Miyoshi (1997), Miyahara and Ooishi (1997), so the description of the GCM is briefly mentioned here.

The GCM has a full set of physical processes, such as radiation, a boundary layer, hydrology, moist and dry convection, and vertical eddy diffusion. In the middle atmosphere, Strobel's parameterization (Strobel, 1978) is used for the solar radiation by $\mathrm{O}_{3}$ and $\mathrm{O}_{2}$, while Fomichev's parameterization (Fomichev et al., 1985, 1993) is used for the long wave radiation by $\mathrm{O}_{3}$ and $\mathrm{CO}_{2}$. In the lower thermosphere, the long wave radiation by NO is also parameterized by Kockarts's method (Kockarts, 1980). The distributions of $\mathrm{O}_{3}, \mathrm{O}_{2}, \mathrm{CO}_{2}$ and $\mathrm{NO}$ are climatologically prescribed. In the upper mesosphere and lower thermosphere, the density of the atmosphere becomes extremely low, so the diffusion of momentum and heat due to the molecular viscosity and conductivity is introduced. Furthermore, the momentum exchange 


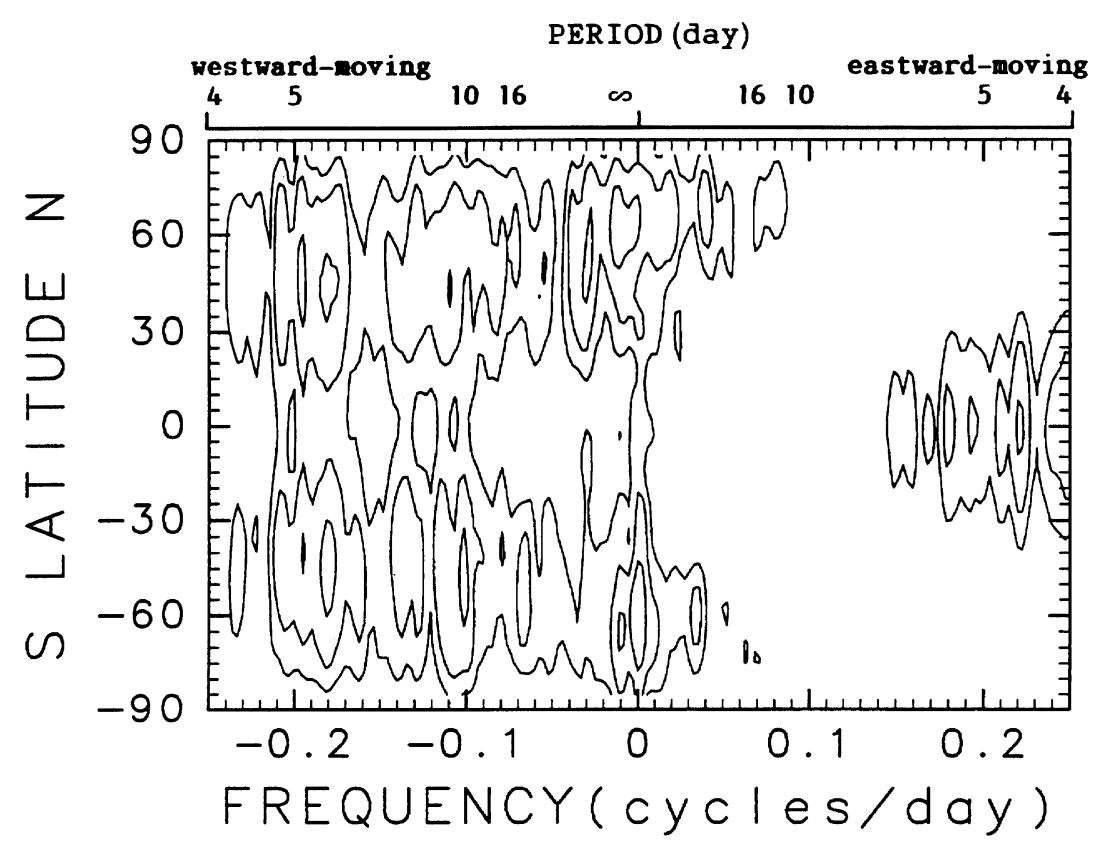

Fig. 1(a). Latitude-frequency distribution of the spectral analysis of geopotential height at $100 \mathrm{~km}$ height for $s=1$. Contour values are $10,20,40,80$ and $160 \mathrm{~m}$.

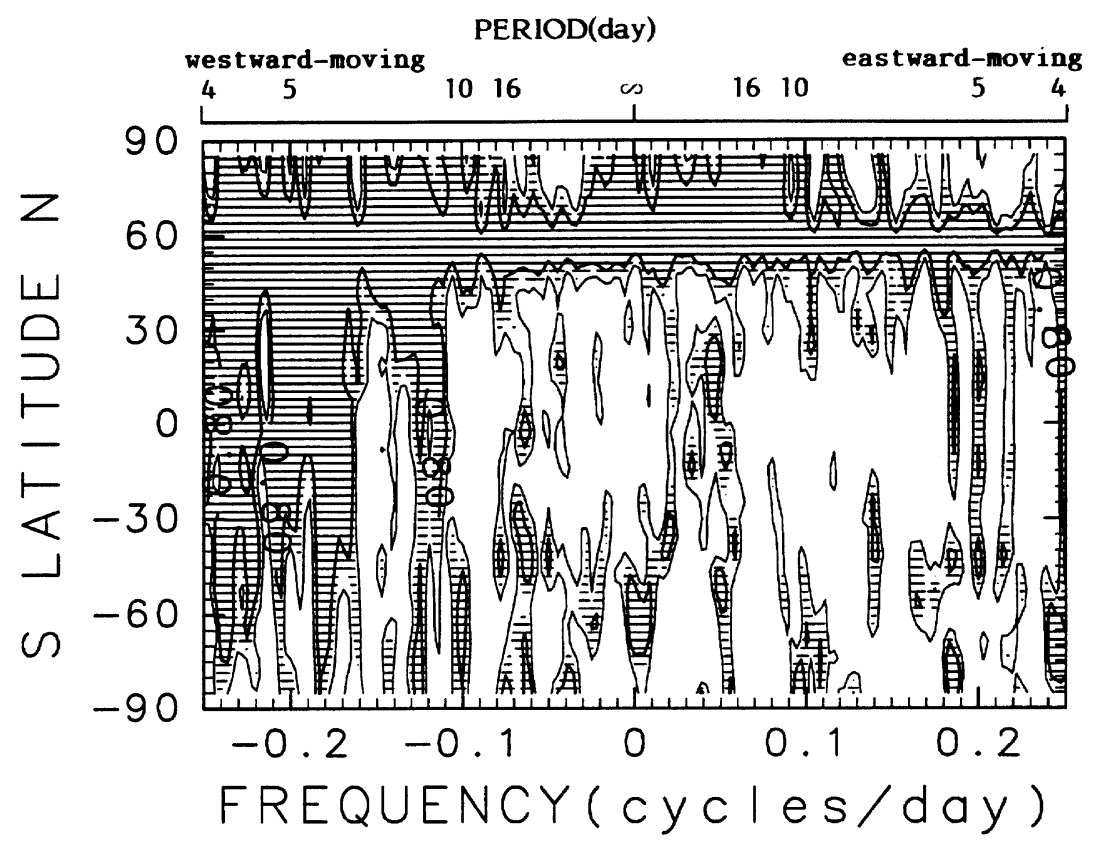

Fig. 1(b). Latitude-frequency distribution of the coherence squared of $s=1$ at $100 \mathrm{~km}$ for the same season as that in Fig. 1(a). The reference latitude is $60^{\circ}$ N. Contour values are 0.6 and 0.8 . Shading region denotes greater than 0.7 .

between the neutral atmosphere and the ionized atmosphere is also taken into account, because the density of the ionized atmosphere is not negligible. In the mesosphere, a Rayleigh friction to weaken the zonal mean zonal wind is introduced for a crude approximation of the gravity wave drag.

The data is sampled every 6 hours for 12 months. To extract westward moving components of $s=1$, the Fourier transform based on Hayashi (1971) is performed. Next, a numerical band-pass filter by Ormsby (Ormsby, 1961) is used to separate the dominant frequency components. A westward moving component of $s=1$ with a period from 4.4 to 6.0 days is extracted for the 5-day wave, while a westward moving component of $s=1$ with a period from 12.0 to 24.0 days is extracted for the 16-day wave. The observed range of 

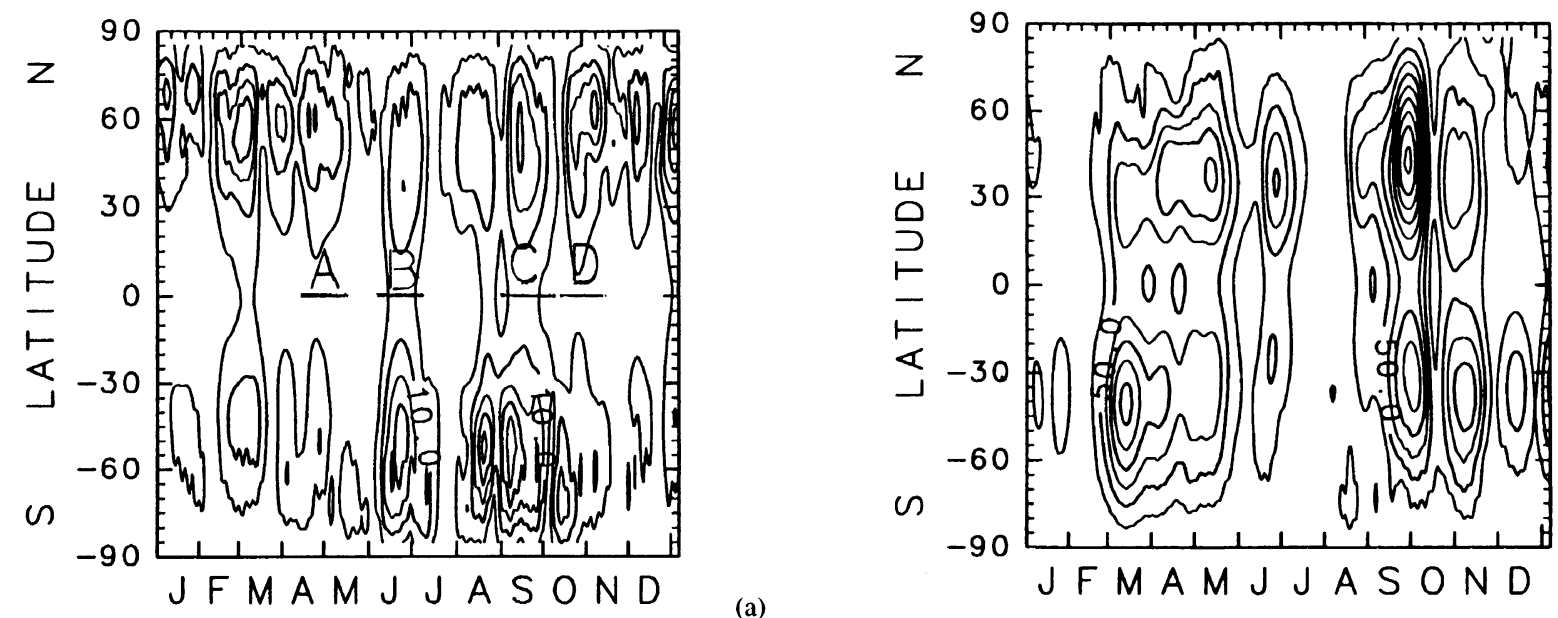

(a)
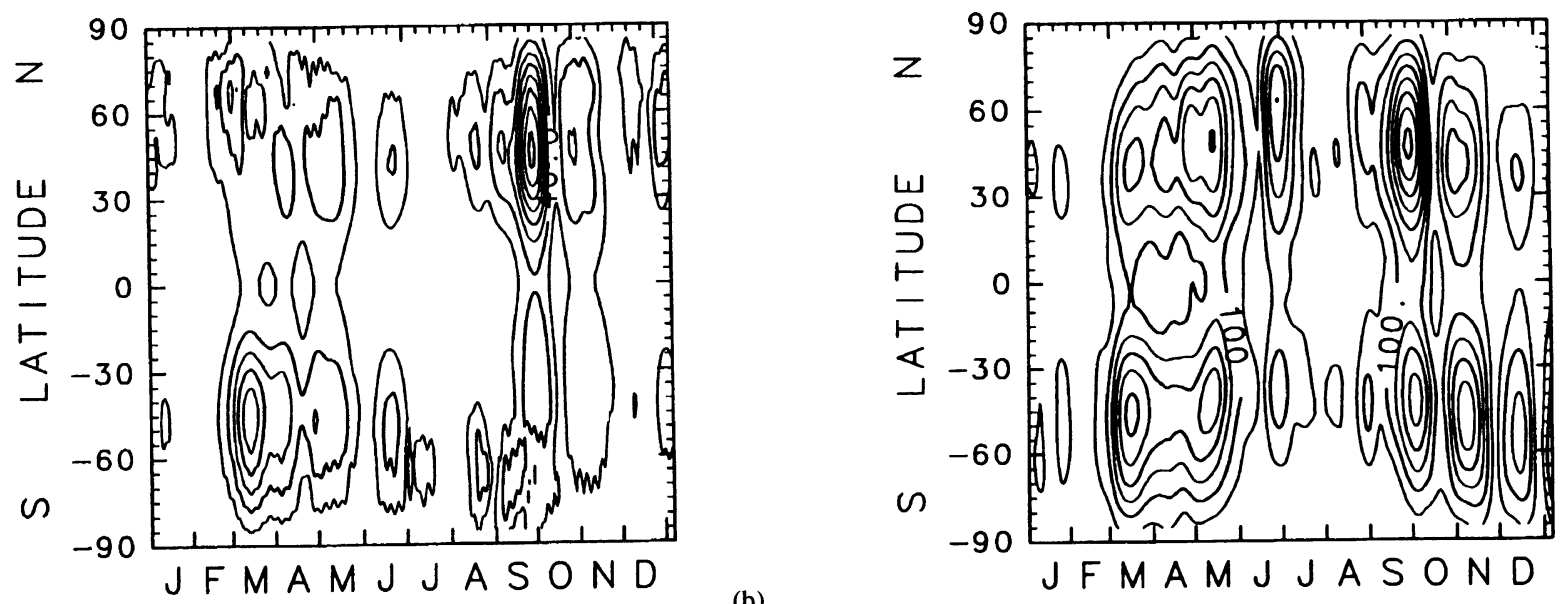

(b)

(d)

Fig. 2. (a) Time-latitude section of the amplitude of the 5-day wave at $25 \mathrm{~km}$ height. Contour interval is $5 \mathrm{~m}$. (b) As in (a), but for $50 \mathrm{~km}$ height. Contour interval is $20 \mathrm{~m}$. (c) As in (a), but for $75 \mathrm{~km}$ height. Contour interval is $25 \mathrm{~m}$. (d) As in (a), but for $100 \mathrm{~km}$ height. Contour interval is $50 \mathrm{~m}$.

periods of the 16-day wave is usually quoted to be $12-14$ to 19-20 days, so our range for the 16-day wave may be somewhat wider. However, observational study by Hirooka and Hirota (1984) revealed that the spectral peaks in the upper stratosphere were seen in the period band of 13-24 days. In this study, a wider range of periods is used.

\section{Results}

\subsection{The 5-day wave}

Figure 1(a) shows a latitude-frequency distribution of power spectra of geopotential height at $100 \mathrm{~km}$ height of $s=1$ for one year. For westward moving components, spectral peaks appear at about 5, 10 and 16 days period. To make sure of the predominance wave, the cross spectral analysis at $100 \mathrm{~km}$ of $s=1$ for one year is performed. The $60^{\circ} \mathrm{N}$ is chosen as the reference latitude. Figure 1(b) shows a latitude-frequency distribution of the coherence squared. The strong coherence appears at 5,10 and 16 day periods of the westward moving component. These peaks corresponds to the 5-day, 10-day $((1,2)$ mode) and 16-day waves.

The behavior of the 5-day wave is firstly examined. To detect the 5-day wave, westward moving component of $s=1$ with a period from 4.4 to 6.0 days is obtained. Figure 2 shows a time-latitude section of the amplitude of the 5-day wave in the stratosphere, mesosphere and lower thermosphere. Because the 5-day wave is largely unaffected by the background wind (Geisler and Dickinson, 1976), the 5-day wave appears throughout the year. The amplitude of the 5-day wave is 10$25,40-140,50-200$ and $100-300 \mathrm{~m}$ at $25,50,75$ and 100 $\mathrm{km}$ height, respectively.

Figure 3(a) shows a latitudinal phase difference between $41.5^{\circ} \mathrm{N}$ and $41.5^{\circ} \mathrm{S}$ at $100 \mathrm{~km}$ height. Latitudinal differences at other latitudes are also small. The symmetric structure about the equator is dominant. At other vertical levels, the symmetric structure about the equator is also clear (not shown). Figure 3(b) shows vertical growth rate of the amplitude during the predominant periods of the 5-day wave. Above $100 \mathrm{~km}$ height, the amplitude of the 5-day wave decreases with height. This may be due to the strong dissipation processes, such as molecular and eddy viscosities and radiative damping, in the lower thermosphere. Below $100 \mathrm{~km}$ height, the growth rate of the amplitude is close to that of the theoretically expected Lamb mode. However, the growth rate of the amplitude varies somewhat with the seasons. In the upper mesosphere and lower thermosphere, the amplitude of the 5-day wave in the summer hemisphere is larger than that 


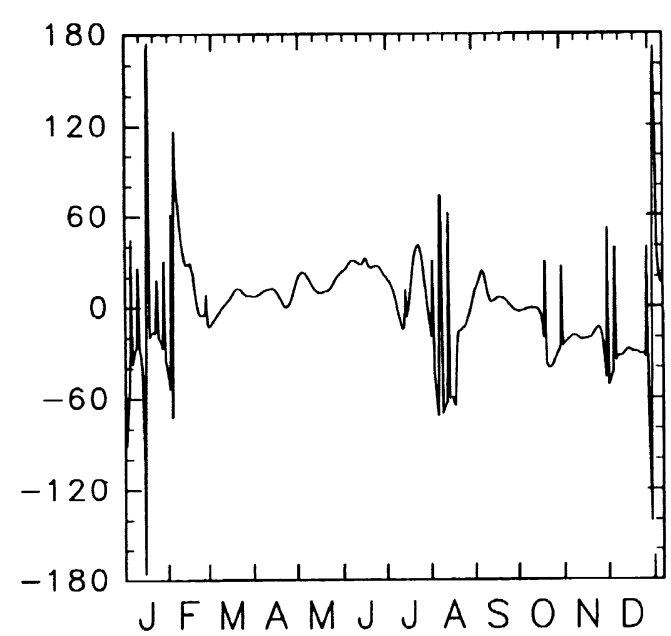

(a)

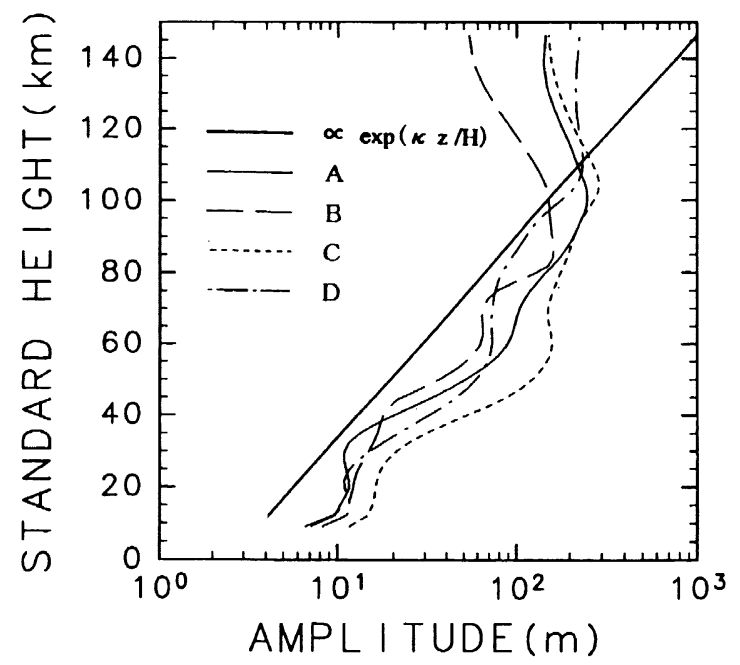

(b)

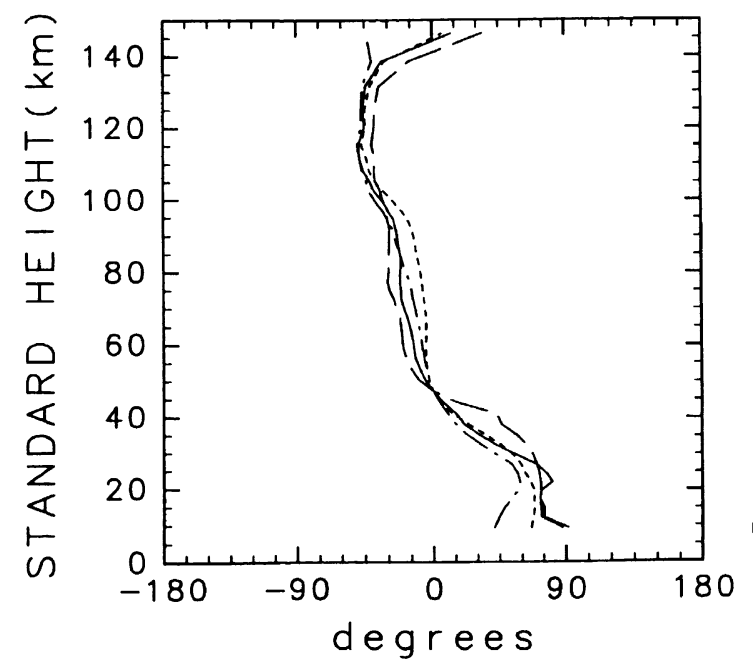

Fig. 3. (a) Time series of latitudinal phase difference between $41.5^{\circ} \mathrm{N}$ and $41.5^{\circ} \mathrm{S}$. Units are degrees. (b) Amplitude of the 5-day wave at $41.5^{\circ} \mathrm{N}$ for the four predominant periods in Fig. 2(a). (c) Vertical phase difference between $1 \mathrm{hPa}$ and other levels at $41.5^{\circ} \mathrm{N}$ for the same periods as in (b).

in the winter hemisphere (e.g., case B in Fig. 2). On the other hand, in the stratosphere, the amplitude in the summer hemisphere is smaller than that in the winter hemisphere. The growth rate of the amplitude in the mesosphere is somewhat

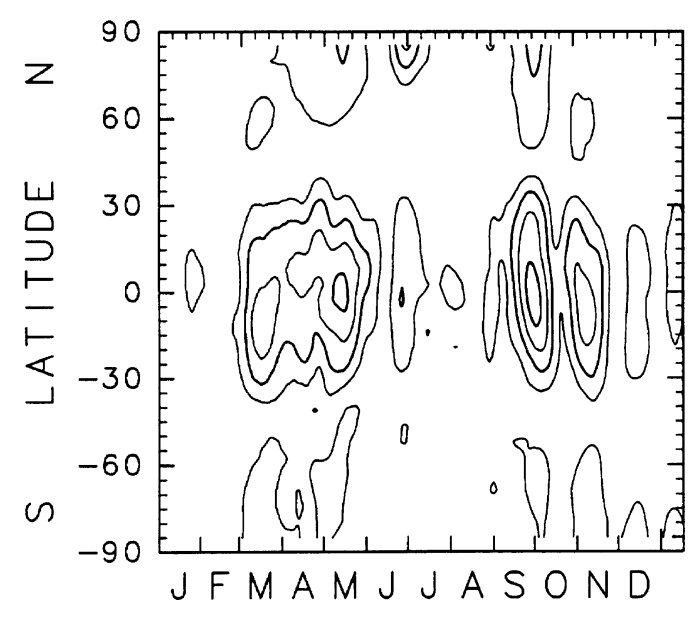

Fig. 4. Time-latitude section of the zonal wind component of the 5-day wave at $100 \mathrm{~km}$ height. Contour interval is $4 \mathrm{~ms}^{-1}$.

larger in the summer hemisphere than in the winter hemisphere. Figure 3(c) shows relative vertical phase differences during the predominant periods of the 5-day wave. There is a small westward phase tilt with height. Thus, the vertical and horizontal structure of the simulated 5-day wave is similar to that of the theoretically expected normal mode Rossby waves. Figure 4 shows a time-latitude section of the amplitude of the zonal wind component due to the 5-day wave at $100 \mathrm{~km}$ height. The peak amplitude in the zonal component ranges between 10 and $18 \mathrm{~ms}^{-1}$. This value is in good agreement with the UARS observations (e.g., Wu et $a l ., 1994)$. Thus, the 5-day wave with a lifetime of 20 to 40 days is clearly seen throughout the middle atmosphere. The enhancement of the 5-day wave in the upper mesosphere and lower thermosphere occurs simultaneously with that in the stratosphere.

\subsection{The 16-day wave}

In this subsection, the behavior of the 16-day wave is investigated. Figures 5(a) and 5(b) show a time-latitude section of the amplitude of the 16-day wave at $25 \mathrm{~km}$ and $50 \mathrm{~km}$ height. In the lower stratosphere, although the amplitude of the 16-day wave in the summer hemisphere is small, the 16-day wave with a lifetime of 1-2 months appears throughout the year. On the other hand, in the winter hemisphere of the upper stratosphere, the asymmetry of the amplitude becomes large because of the asymmetry of the zonal mean zonal wind in the stratosphere. These features are consistent with the observation (Hirooka and Hirota, 1984).

Figure 5 shows a time-latitude section of the amplitude of the 16-day wave in the upper mesosphere and lower thermosphere. Above the upper mesosphere, the 16-day wave appears not only in the winter hemisphere but also in the summer hemisphere. Figure 6 shows time variation of the latitudinally averaged amplitude of the 16-day wave in the stratosphere, mesosphere and lower thermosphere. The enhancement of the latitudinally averaged amplitude in the upper mesosphere and lower thermosphere occurs when the amplitude in the stratosphere becomes large.

Next, a detailed analysis of the 16-day wave in the equinoc- 


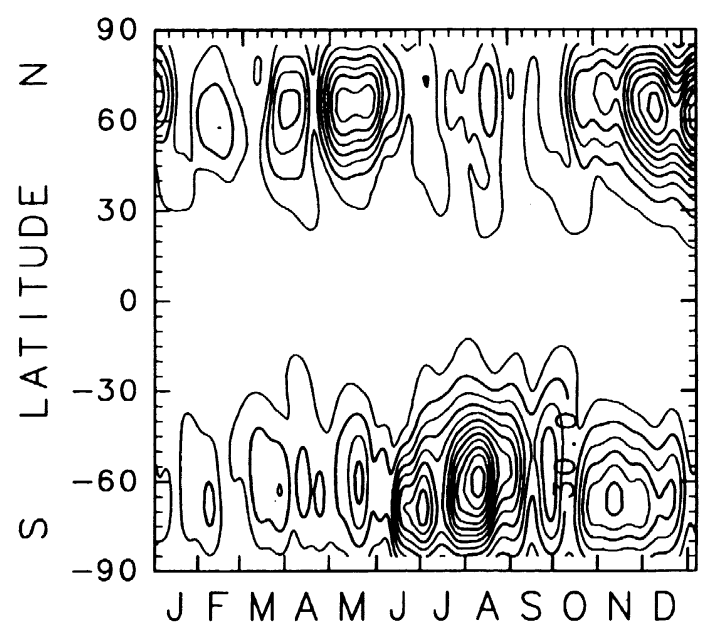

(a)
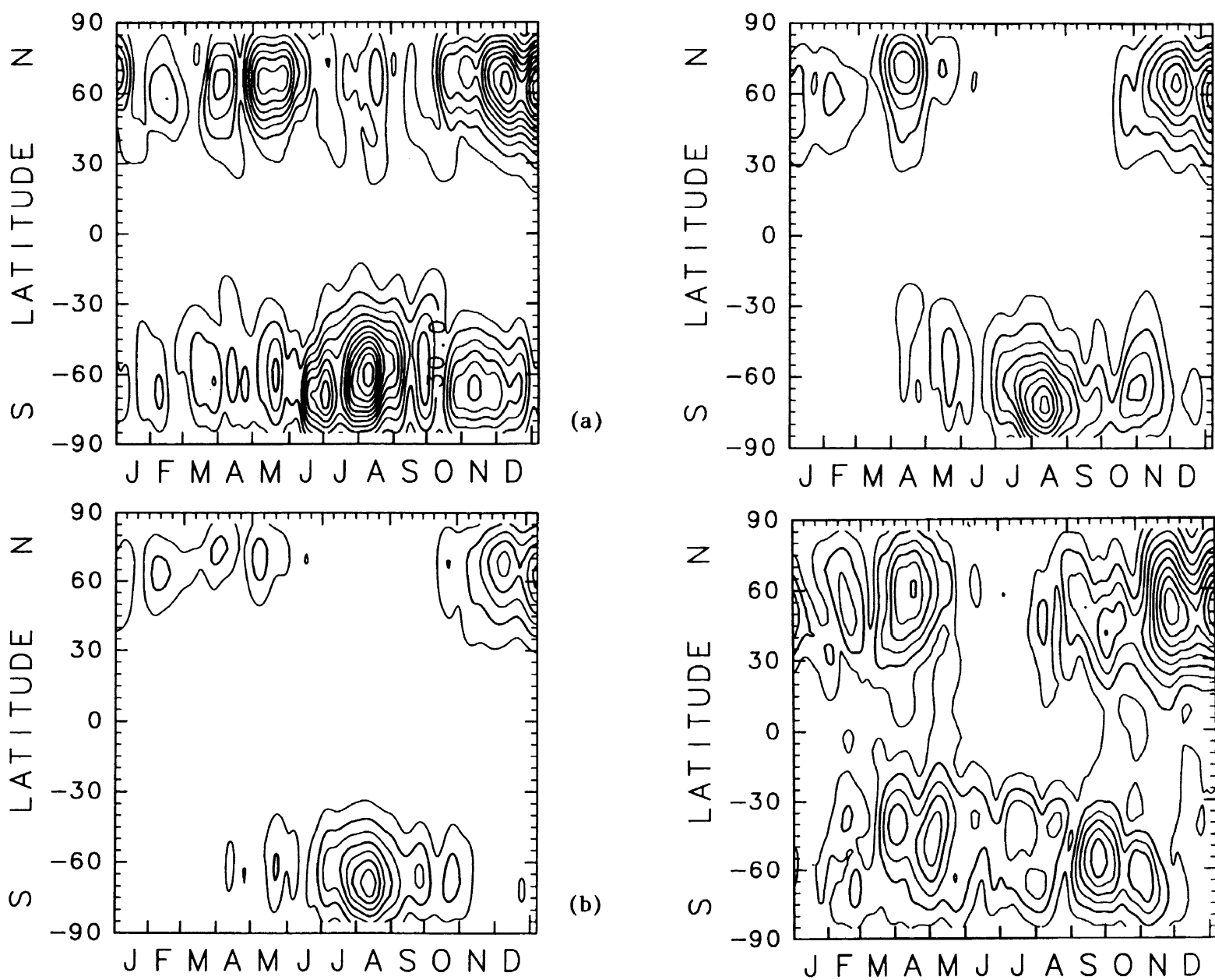

(c)

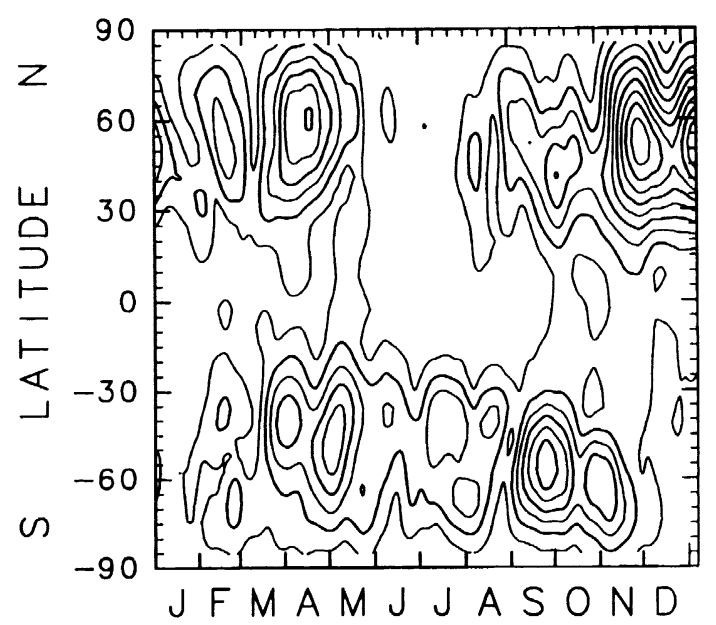

Fig. 5. (a) Time-latitude section of the amplitude of the 16-day wave at 25 $\mathrm{km}$ height. Contour interval is $15 \mathrm{~m}$. (b) As in (a), but for $50 \mathrm{~km}$ height. Contour interval is $100 \mathrm{~m}$. (c) As in (a), but for $75 \mathrm{~km}$ height. Contour interval is $50 \mathrm{~m}$. (d) As in (a), but for $100 \mathrm{~km}$ height. Contour interval is $25 \mathrm{~m}$. (e) As in (a), but for $120 \mathrm{~km}$ height. Contour interval is $25 \mathrm{~m}$.

tial season is performed. Figure 7(a) shows a latitude-height section of the amplitude of the 16-day wave averaged from April 1 to April 10. The maximum amplitude is $320 \mathrm{~m}$ in the northern hemisphere and $120 \mathrm{~m}$ in the southern hemisphere, which appears near the mesopause. Figure 7(b) shows the distribution of zonal mean zonal wind during the same period, and Fig. 7(c) shows the refractive index for the 16-day wave (e.g., Matsuno, 1970). The strong easterly does not exist, and the positive region of the refractive index spreads over both the hemispheres of the middle atmosphere except for low latitudes and polar regions. This positive region of the refractive index indicates that the 16-day wave can have global structure throughout the middle atmosphere. In the equinoctial season, the vertical penetration of the 16-day wave occurs in both the hemispheres.

The behavior of the 16-day wave in the summer season of the northern hemisphere is examined. Figure 8(a) shows a latitude-height section of the amplitude of the 16-day wave averaged from August 1 to August 10. In the summer hemisphere of the stratosphere and mesosphere, the amplitude of the 16-day wave is very small. However, near the mesopause

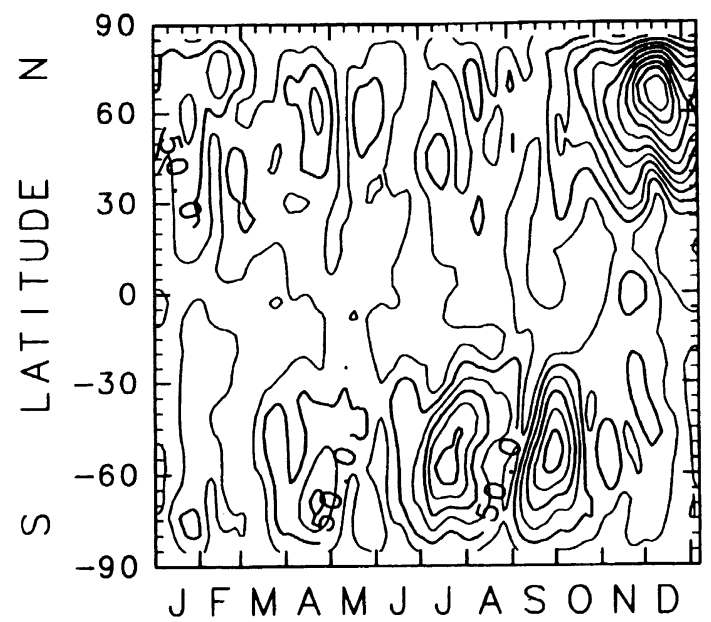

(e)

Fig. 5. (continued).

region, the amplitude in the summer hemisphere increases with height, and the 16-day wave has global structure. Figure 8 (b) shows the distribution of zonal mean zonal wind during the same period. The easterly and westerly jets in the mesosphere decrease with height, and the weak zonal wind region exists in the mesopause region. This feature are in good agreement with the observation. However, in the lower thermosphere, the reversal of the zonal wind is unclear. The westerly in the summer hemisphere and the easterly in the 


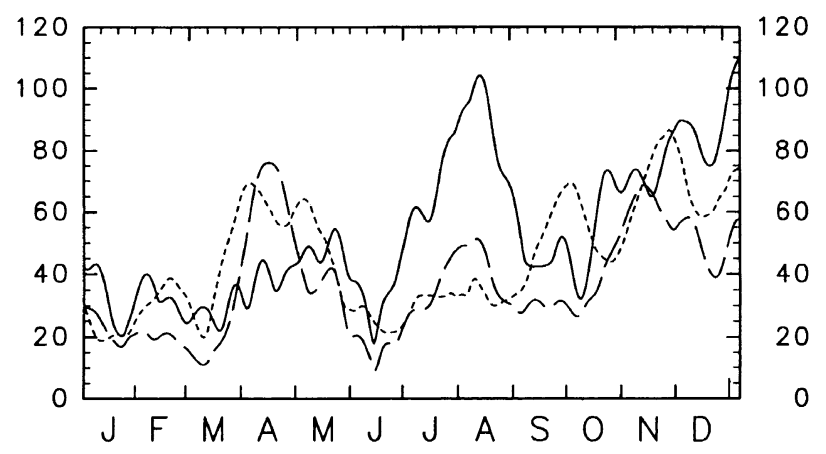

Fig. 6. Time series of the latitudinally averaged amplitude of the 16-day wave at 50 (solid line), 75 (broken line) and 100 (dotted line) $\mathrm{km}$ height. Units are $\mathrm{m}$.

winter hemisphere is not clearly seen. This is not consistent with the observation (e.g., CIRA, 1986). This discrepancy is considered to be due to the weak gravity drag in the GCM because of the low horizontal resolution of the GCM. The 16-day wave is sensitive to the zonal wind variation, so the discrepancy of the zonal wind above the lower thermosphere may affect the amplitude of the 16-day wave in the lower thermosphere.

However, the weak wind region near the mesopause is obtained, so we discuss the behavior of the 16-day wave near the mesopause region. Figure 8(c) shows the refractive index for the 16-day wave in early August. In the mesosphere, the refractive index in the summer hemisphere is negative because of the strong easterly, and the positive region appears in the winter hemisphere. On the other hand, near the mesopause region, the positive region spreads over at all latitudes. This result indicate that the 16-day wave can have global structure in the mesopause region. The 16-day wave in the winter hemisphere of the stratosphere and mesosphere has large amplitude. These results indicate that the penetration of the 16-day wave from the winter hemisphere into the summer hemisphere occurs near the mesopause region. Forbes et al. (1995) showed that the 16-day wave penetration into the summer hemisphere was sensitive to the mean zonal wind distribution above about $80 \mathrm{~km}$ height. Thus, we may need further studies to investigate the behavior of the 16-day wave in the mesopause region under the more realistic zonal wind distribution.

The amplitude of the lower thermosphere in August is 60 $80 \mathrm{~m}$ in the northern hemisphere, and $100-160 \mathrm{~m}$ in the southern hemisphere. Above $100 \mathrm{~km}$ height, the 16-day wave has global structure, although the negative region spreads over the northern hemisphere (Fig. 8(c)). Effects of the vertical diffusion due to the molecular viscosity become large above $100 \mathrm{~km}$ height, so that the refractive index may not be good indicator for wave activity above $100 \mathrm{~km}$ height.

\subsection{Excitation sources of the 16-day wave}

Though the 5-day and 16-day waves are free oscillation modes of the atmosphere, some excitation sources for the 5-day and 16-day waves are required to overcome the dissipation processes in the atmosphere. As for excitation sources of the 5-day wave, Miyoshi and Hirooka (1999) shows that

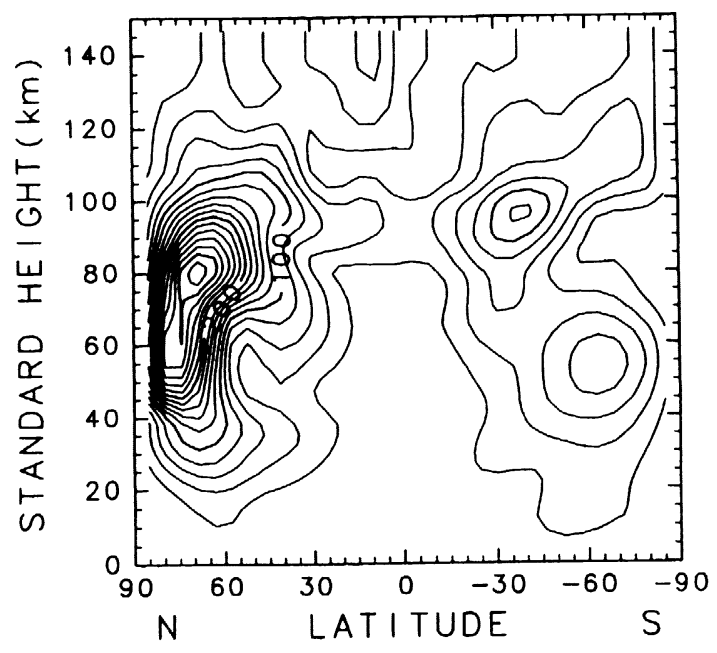

(a)
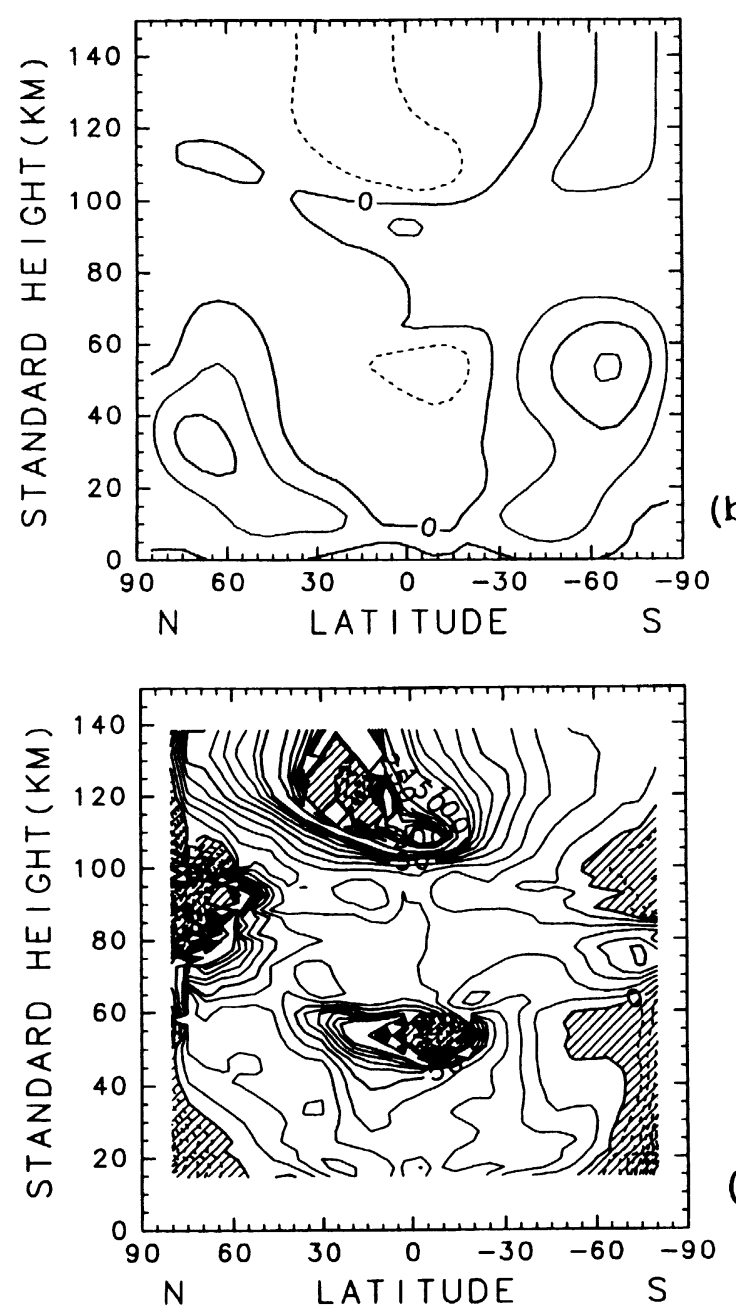

(c)

Fig. 7. (a) Latitude-height section of the amplitude of the 16-day wave averaged from April 1 to April 10. Contour interval is $20 \mathrm{~m}$. (b) As in (a), but for the zonal mean zonal wind. Contour interval is $20 \mathrm{~ms}^{-1}$. Solid and broken lines represent westerly and easterly, respectively. (c) As in (a), but for the refractive index for the 16-day wave. Contour interval is 10. Negative values are shaded.

the heating process due to the moist convection in the troposphere is important for excitation of the 5-day wave. They also indicate that effects of mountains and land-sea contrast 

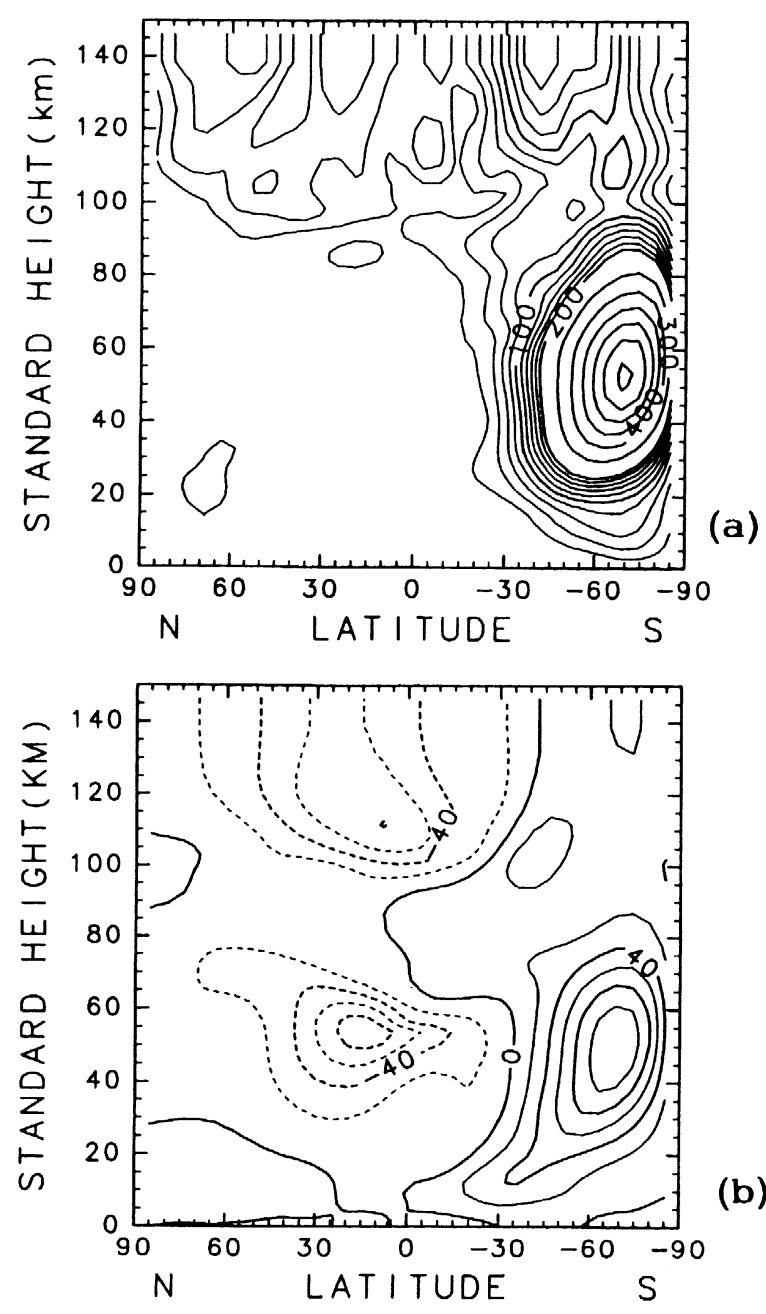

(b)

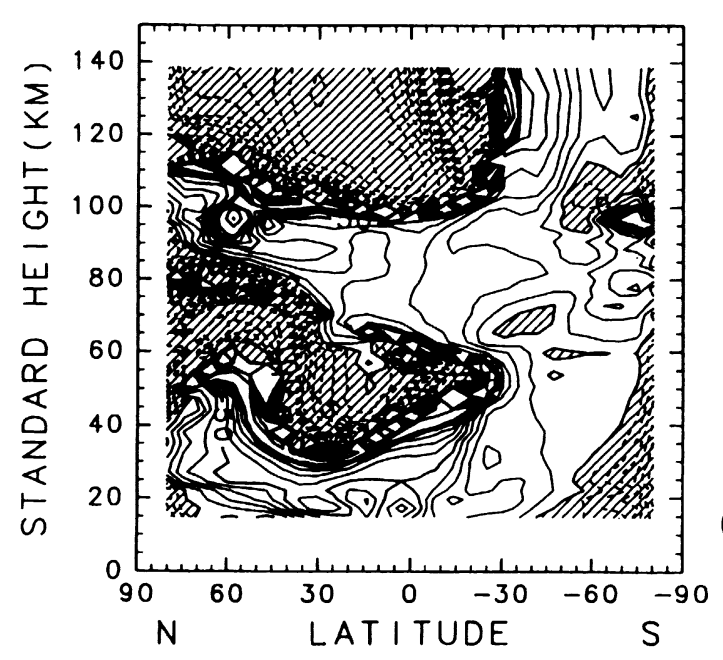

(c)

Fig. 8. (a) Latitude-height section of the amplitude of the 16-day wave averaged from August 1 to August 10. Contour interval of thick lines and thin lines is 100 and $20 \mathrm{~m}$, respectively. (b) As in (a), but for the zonal mean zonal wind. Contour interval is $20 \mathrm{~ms}^{-1}$. Solid and broken lines represent westerly and easterly, respectively. (c) As in (a), but for the refractive index for the 16-day wave. Contour interval is 10. Negative values are shaded. on excitation of the 5-day wave are not essential. In this subsection, we investigate excitation sources of the 16-day wave in the troposphere. Effects of mountains, land-sea contrast and moist convection on excitation of the 16-day wave are investigated by a series of GCM experiments, which is similar to Miyoshi and Hirooka (1999). Namely, GCM experiments without mountains, with uniform lower boundary and with the dry atmosphere are performed. Model design is summarized in Table 1 . To exclude effects of seasonal variation, the season is fixed at equinox condition in all the experiments. By comparing the magnitude of the 16-day wave in these experiments, excitation sources will be made clear.

EXP-1 in Table 1 is the control experiment, and is the same as the experiment described in the previous sections except for seasonal variation. The amplitude of the 16-day wave at $20 \mathrm{~km}$ height in the control experiment is $30-75 \mathrm{~m}$ (Fig. 9(a)). Figure 9(b) is the amplitude of the 16-day wave in the experiment without mountains (EXP-2 in Table 1). In EXP-2, effects of land-sea contrast and the moist convection are taken into account. The amplitude in EXP-2 is 30-90 m. The 16-day wave is clearly seen in no mountains case, and the amplitude of the 16-day wave with no mountains case is similar to that in the control experiment. Hayashi and Golder (1984) investigated transient Rossby waves in the tropospheric GFDL GCM with and without mountains. They showed that the 16-day wave appeared in the experiment without mountains. Their result is consistent with our result.

Figure 9(c) shows the amplitude of the 16-day wave in the experiment with uniform lower boundary (EXP-3). In this experiment, the ground surface is assumed to be covered by swamp ocean everywhere. The amplitude of the 16-day wave is $30-75 \mathrm{~m}$. The amplitude during days $90-270$ is somewhat smaller than that in the control experiment. Thus, the amplitude of the 16-day wave is affected by effects of land-sea contrast. However, the 16-day wave has considerable amplitude in the uniform boundary case.

Figure 9(d) shows the amplitude of the 16-day wave in the experiment without the moist convection (EXP-4). In this experiment, the mixing ratio of water vapor in the atmosphere is assumed to be 0 . The ground surface is assumed to be uniform and dry everywhere. The amplitude of the 16day wave is $5-15 \mathrm{~m}$, which is much smaller than that in the other experiments (EXP-1, 2, 3). These results indicate that heating due to the moist convection is the most important forcing for the 16-day wave. Effects of land-sea contrast are not negligible, but are not essential. Thus, the 16-day wave is mainly excited by the moist convection, and the vertical penetration of the 16-day wave into the mesosphere occurs.

\section{Discussion}

In this section, we discuss the wind variation associated with normal mode Rossby waves, and its relation to the geomagnetic variation. Forbes and Leveroni (1992) suggested that upward penetration of normal mode Rossby waves which is excited in the lower atmosphere, occurred and induced the geomagnetic variation. They showed that a 16-day oscillation of order $10 \mathrm{~ms}^{-1}$ at $100-150 \mathrm{~km}$ height was required to explain the observed geomagnetic variation with a 16-day period.

Figure 10 shows a time-latitude section of the zonal wind 
Table 1. Description of experimental design.

\begin{tabular}{ccccc}
\hline & $\begin{array}{c}\text { Effects of } \\
\text { seasonal variation }\end{array}$ & $\begin{array}{c}\text { Effects of } \\
\text { mountains }\end{array}$ & $\begin{array}{c}\text { Effects of } \\
\text { land-sea contrast }\end{array}$ & $\begin{array}{c}\text { Effects of } \\
\text { moist convection }\end{array}$ \\
\hline EXP-1 & $\times$ & $\bigcirc$ & $\bigcirc$ & $\bigcirc$ \\
EXP-2 & $\times$ & $\times$ & $\bigcirc$ & $\bigcirc$ \\
EXP-3 & $\times$ & $\times$ & $\times$ & $\bigcirc$ \\
EXP-4 & $\times$ & $\times$ & $\times$ & $\times$ \\
\hline
\end{tabular}
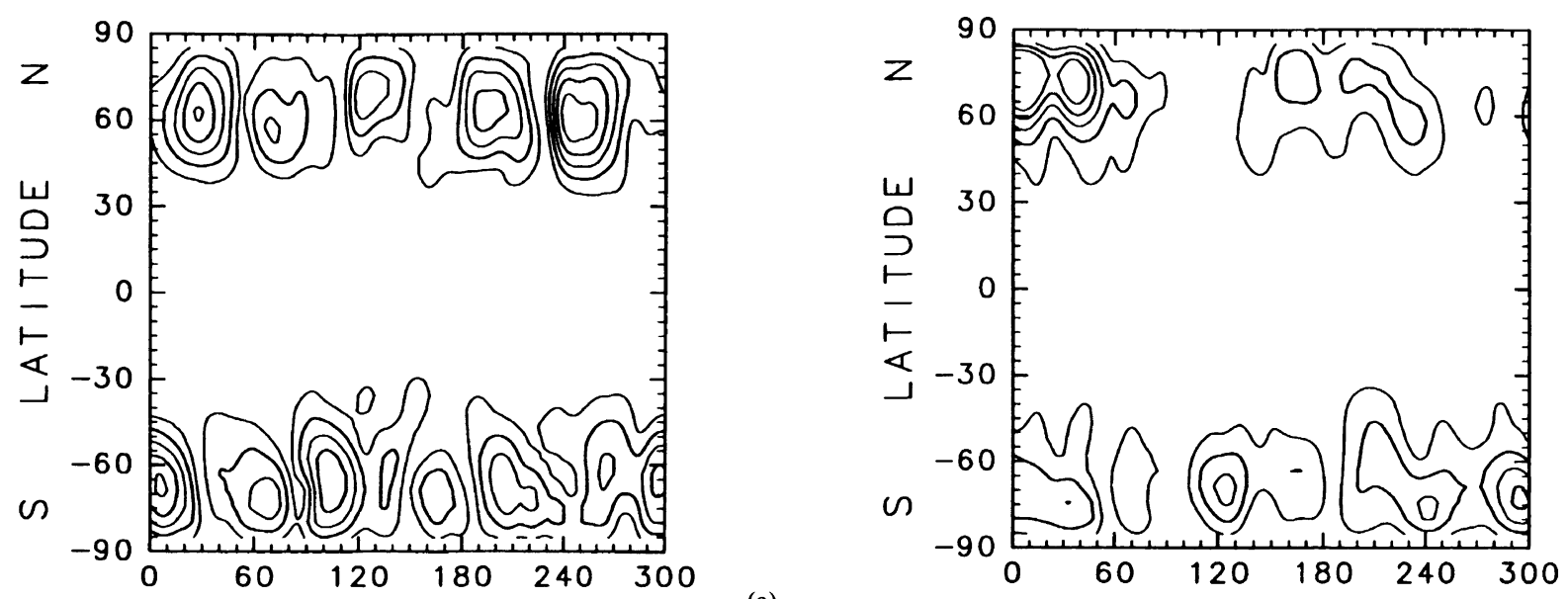

(a)
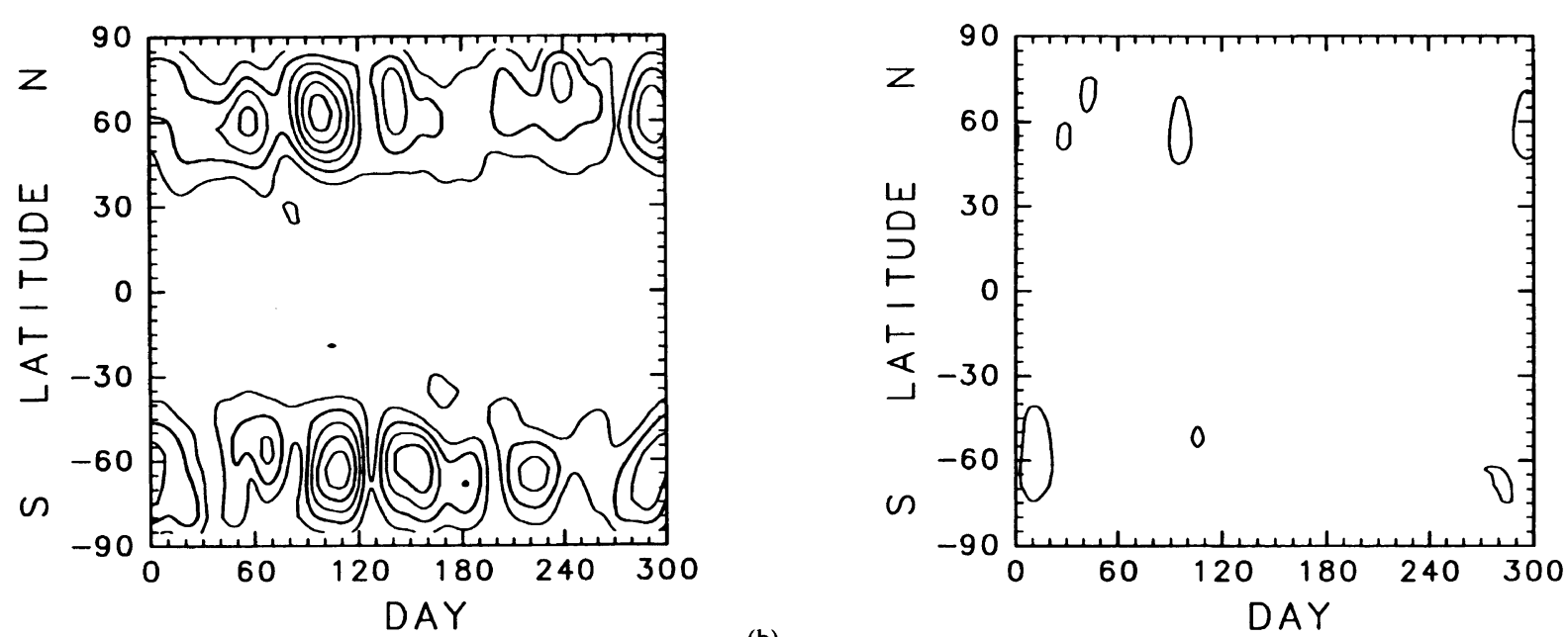

(b)

Fig. 9. (a) Time-latitude section of the amplitude of the 16-day wave at $20 \mathrm{~km}$ height in the control experiment (EXP-1). Contour interval is $15 \mathrm{~m}$. (b) Time-latitude section of the amplitude of the 16-day wave at $20 \mathrm{~km}$ height in the experiment without mountains (EXP-2). Contour interval is $15 \mathrm{~m}$. (c) Time-latitude section of the amplitude of the 16-day wave at $20 \mathrm{~km}$ height in the experiment with uniform lower boundary (EXP-3). Contour interval is $15 \mathrm{~m}$. (d) Time-latitude section of the amplitude of the 16-day wave at $20 \mathrm{~km}$ height in the experiment without the moist convection (EXP-4). Contour interval is $15 \mathrm{~m}$.

component of the 16-day wave at 100 and $120 \mathrm{~km}$ height. The zonal wind component at $100 \mathrm{~km}$ height is $6-8 \mathrm{~ms}^{-1}$. The magnitude of the zonal wind component decreases with height because of the strong dissipation processes in the lower thermosphere. These values are somewhat smaller than the value estimated by Forbes and Leveroni (1992). These re- sults are consistent with Forbes et al. (1995). As shown by Forbes et al., a secondary source above the mesopause region is required. However, Kohsiek et al. (1995) suggested that there is a correlation between the geomagnetic variation and the 16-day wave. Miyahara and Ooishi (1997) showed that the day-to-day variation can be induced by the neutral wind 


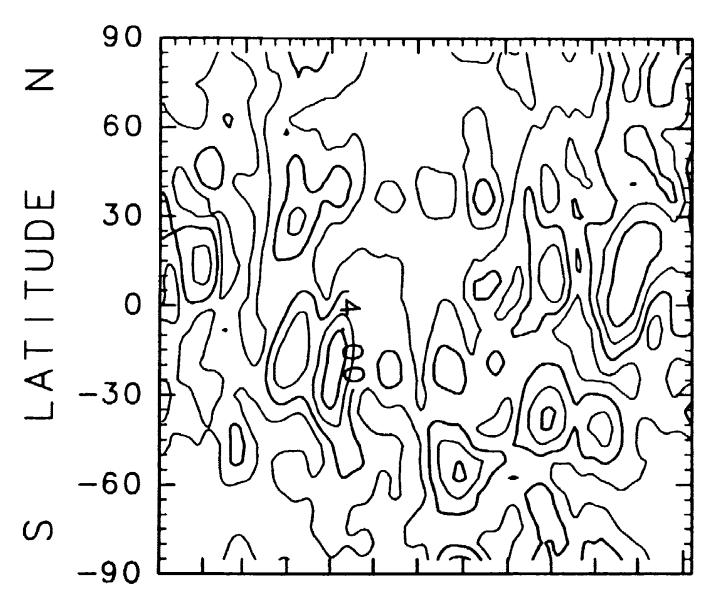

(a)

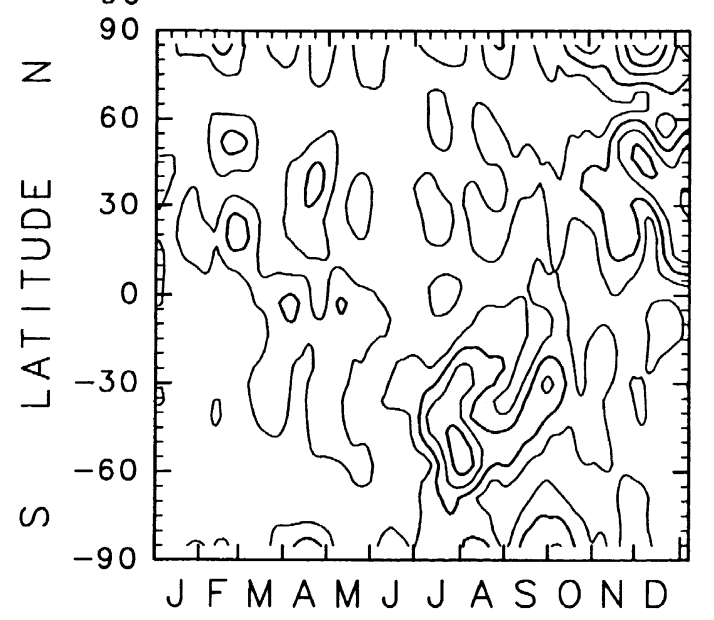

(b)

Fig. 10. (a) Time latitude section of the zonal wind component of the 16-day wave at $100 \mathrm{~km}$ height in the control experiment. Contour interval is $2 \mathrm{~ms}^{-1}$. (b) As in (a), but for $120 \mathrm{~km}$ height.

variation in the lower thermosphere simulated by the Kyushu University GCM. Thus, our results suggest that the observed geomagnetic variation is partly induced by the 16-day wave excited in the troposphere. In our experiment, the zonal mean zonal wind distribution in the lower thermosphere of the solstitial season is not realistic, so that this discrepancy may affect the 16-day wave amplitude in the lower thermosphere. We need further numerical experiments by using more realistic zonal wind distribution.

As shown in Fig. 4, the zonal wind component of the 5-day wave at $100 \mathrm{~km}$ height is $10-18 \mathrm{~ms}^{-1}$, which is larger than that of the 16-day wave. The zonal wind component of the 5 -day wave at $120 \mathrm{~km}$ height is about $10 \mathrm{~ms}^{-1}$. In figure 2 of Forbes and Leveroni (1992), the geomagnetic variation with about a 5-day period also appears. Thus, these results suggest that the zonal wind variation due to the 5-day wave, which is excited in the troposphere, may induce the geomagnetic variation with a 5 day period.

We showed that the 16-day wave was excited mainly by heating due to the moist convection. Miyoshi and Hirooka (1999) showed that the 5-day wave was also excited by the moist convection. The penetration of the 5-day and 16-day waves into the lower thermosphere occurred. Based on these results, it is suggested that there may be the correlation be- tween the moist convective activity in the troposphere and the geomagnetic variability in the thermosphere. However, we need further observational and numerical studies to investigate this relation. This will be a subject of the future study.

\section{Summary}

In this study, we investigated excitation of the 5-day wave by a series of GCM experiments. The results are as follows:

(1) The 5-day wave is largely unaffected by the zonal mean zonal wind distribution and the symmetric structure about the equator is clearly seen in the mesopause region. The enhancement of the 5-day wave in the mesopause region occurs simultaneously with that in the stratosphere.

(2) The amplitude of the 16-day wave is large in the winter hemisphere of the stratosphere and lower mesosphere. On the other hand, above the upper mesosphere, the 16day wave appears not only in the winter hemisphere but also in the summer hemisphere. The penetration of the 16-day wave from the winter hemisphere to the summer hemisphere occurs near the mesopause region.

(3) The 16-day wave is mainly excited by heating due to the moist convection in the troposphere.

(4) We suggest that there is a correlation between the geomagnetic variation and the wind variation due to normal mode Rossby waves.

Acknowledgments. We wish to thank Professor S. Miyahara, Professor T. Hirooka, and Dr. K. Nakajima for their helpful discussions and comments. Thanks are also due to anonymous reviewers for their suggestions to improve the manuscript. This work was supported in part by the Grant-in-Aid for Scientific Research, the Ministry of Education, Science, Culture and Sports. GFD-DENNOU library was used for drawing figures.

\section{References}

CIRA86, COSPAR International Reference Atmosphere 1986 Part 2: Middle atmosphere, edited by D. Rees, J. J. Barnett, and K. Labitzke, 519 pp., Pergamon Press, Oxford, 1988.

Espy, P. J. and G. Witt, Observation of a quasi 16-day oscillation in the polar summer mesospheric temperature, Geophys. Res. Lett., 23, 1071-1074, 1996.

Fomichev, V. I. and G. M. Shved, Parameterization of the radiative flux divergence in the $9.6 \mu \mathrm{m} \mathrm{m} \mathrm{O}_{3}$ band, J. Atmos. Terr. Phys., 47, 1037 1049, 1985.

Fomichev, V. I., A. A. Kutepov, R. A. Akmaev, and G. M. Shved, Parameterization of the $15 \mu \mathrm{m} \mathrm{m} \mathrm{CO}$ band cooling in the middle atmosphere (15-115 km), J. Atmos. Terr. Phys., 55, 7-18, 1993.

Forbes, J. M. and S. Leveroni, Quasi 16-day oscillation in the ionsphere, Geophys. Res. Lett., 19, 981-984, 1992.

Forbes, J. M., M. E. Hagan, S. Miyahara, F. Vial, A. H. Manson, C. E. Meek, and Y. I. Portnyagin, Quasi 16-day oscillation in the mesosphere and lower thermosphere, J. Geophys. Res., 100, 9149-9163, 1995.

Geisler, J. E. and R. E. Dickinson, The five-day wave on a sphere with realistic zonal winds, J. Atmos. Sci., 33, 632-641, 1976.

Hayashi, Y., A generalized method of resolving disturbances into progressive and retroprogressive waves by space fourier and time cross-spectral analysis, J. Meteor. Soc. Japan, 49, 125-128, 1971.

Hayashi, Y. and D. G. Golder, Transient planetary waves simulated by GFDL spectral general circulation models, Part1: Effects of mountains, J. Atmos Sci., 40, 941-950, 1983.

Hirooka, T. and I. Hirota, Normal mode Rossby waves observed in the upper stratosphere, Part2: Second symmetric modes of zonal wavenumber 1 and 
2, J. Atmos. Sci., 41, 536-548, 1984.

Kockarts, G., Nitric oxide cooling in the terrestrial thermosphere, Geophys. Res. Lett., 7, 137-140, 1980.

Kohsiek, A., K. H. Glassmeier, and T. Hirooka, Periods of planetary waves in geomagnetic variations, Ann. Geophys., 13, 168-176, 1995.

Matsuno, T., Vertical propagation of stationary planetary waves in the winter northern hemisphere, J. Atmos. Sci., 27, 871-883, 1970.

Miyahara, S. and Y. Miyoshi, Migrating and non-migrating atmospheric tides simulated by a middle atmosphere general circulation model, $A d v$. Space Res., 20, 1201-1207, 1997.

Miyahara, S. and M. Ooishi, Variation of Sq induced by atmospheric tides simulated by a middle atmospheric general circulation model, J. Geomag. Geoelectr., 49, 77-87, 1997.

Miyoshi, Y. and T. Hirooka, A numerical experiment of excitation of the 5-day wave by a GCM, J. Atmos. Sci., 56, 1698-1707, 1999.
Ormsby, J. F. A., Design of numerical filters with applications to missile data processing, J. Assoc. Comput. Mach., 8, 440-466, 1961.

Strobel, D. F., Parameterization of the atmospheric heating rate from 15 to $120 \mathrm{~km}$ due to $\mathrm{O}_{2}$ and $\mathrm{O}_{3}$ absorption of solar radiation, J. Geophys. Res., $\mathbf{8 3}, 6225-6230,1978$

Williams, C. R. and S. K. Avery, Analysis of long-period waves using the mesosphere-stratosphere-troposphere radar at Poker Flat, Alaska, $J$. Geophys. Res., 97, 20855-20861, 1992.

Wu, D. L., P. B. Hays, and W. R. Skinner, Observations of the 5-day wave in the mesosphere and lower thermosphere, Geophys. Res. Lett., 21, 2733$2736,1994$.

Y. Miyoshi (e-mail: miyoshi@rossby.geo.kyushu-u.ac.jp) 